\title{
Caffeine-withdrawal headache induced by hemodialysis
}

\author{
Petar M. Nikić · Jasna Zidverc-Trajković • \\ Branislav Andrić • Marija Milinković • \\ Biljana Stojimirović
}

Received: 19 February 2009/Accepted: 23 March 2009/Published online: 15 April 2009

(C) Springer-Verlag 2009

\section{Introduction}

Caffeine is the most widely used psychoactive substance, and caffeinated beverages enjoy immense popularity around the world. Temporal abstinence from caffeine in habitual users results in the well-characterized withdrawal syndrome, consisting mainly of headache, fatigue, tiredness and decreased alertness.

The formal diagnostic criteria for caffeine-withdrawal headache $(\mathrm{CWH})$ were given in the International Classification of Headache Disorders, 2nd edition (ICHD-II). According to these criteria, the headache is bilateral and/or pulsating, occurs when intake is interrupted or delayed in person with caffeine consumption of $\geq 200 \mathrm{~g} /$ day for $>2$ weeks, develops within $24 \mathrm{~h}$ after last caffeine intake and is relieved within $1 \mathrm{~h}$ by $100 \mathrm{mg}$ of caffeine. The obligatory criterion, as for the other secondary headaches, is the improvement or resolution of headache after relief from the causative disorder, e.g. that this headache resolves within 7 days after total caffeine withdrawal. There is a

\section{P. M. Nikić (ه)}

Special Hospital for Cerebrovascular Disease "Sveti Sava", Nemanjina 2, 11000 Belgrade, Serbia

e-mail: persevan@gmail.com

\section{J. Zidverc-Trajković}

Institute of Neurology, Clinical Center Serbia,

Dr Subotića 6, Belgrade, Serbia

B. Andrić

Department of Nephrology, General Hospital, Health Center, Krusevac, Serbia

M. Milinković · B. Stojimirović

Institute of Nephrology, Clinical Center Serbia, Belgrade, Serbia comment on the possibility of this syndrome in patients on dialysis who consume large quantities of caffeine [1, 2].

We report a case of patient on hemodialysis (HD) with CWH. To our best knowledge, there is no published case report on that subject in medical literature.

\section{Case description}

A 59-year-old woman with uremia, due to chronic nephrotic syndrome, has been on regular HD for the last 10 years. She underwent bicarbonate dialysis three times weekly with hemophane membranes.

Her main complaint was headache during the dialysis treatment. The headache typically occurred after $2 \mathrm{~h}$ of therapy, starting with moderate intensity and progressively becoming severe. The maximal intensity of her discomfort was 8 by the verbal analogous scale $(0-10)$. She described her pain as dull, beginning in frontal parts, slowly spreading to occipital regions and then becoming diffuse. There was no associated nausea, photophobia or phonophobia, but she reported tiredness and mild aggravation of symptoms by physical activity. The most distinctive feature of her headache was prompt relief, obtained within $15 \mathrm{~min}$, by drinking a cup of strong black coffee from her coffee-pot she never missed to bring with. Rarely, if the headache persisted, she had to use combined analgesics containing caffeine.

General examination was unremarkable. Other than mild distal sensory loss for all modalities, more pronounced in the lower extremities, her neurological examination was normal. Computed tomography of the head and an electroencephalogram revealed no abnormalities.

Cerebral blood flow (CBF) velocities in middle cerebral artery measured by non-invasive transcranial Doppler (TCD) revealed normal values of $51 \mathrm{~cm} / \mathrm{s}$ on the right and 
$48 \mathrm{~cm} / \mathrm{s}$ on the left side in the beginning of HD, and $55 \mathrm{~cm} /$ $\mathrm{s}$ on the right and $45 \mathrm{~cm} / \mathrm{s}$ on the left side at the end of treatment. Vasomotor reactivity measured by breath holding test was preserved in the first and fourth hours of HD.

Her personal medical record was unremarkable, apart from a history of migraine without aura since teenage years. Ten years ago, when the HD had started the migraine attacks disappeared. She is a non-smoker and consumes four to six cups of boiled black coffee daily from her youth (around 300-450 mg of caffeine). Her son has frequent migraine attacks and a history of habitual coffee consumption as well.

\section{Discussion}

Headache is the most common encountered neurological symptom during HD with the reported frequencies in various studies from 27.6 to $70 \%$ [3, 4]. The differential diagnosis of headache disorders in patients on HD is challenging and many underlying mechanisms have been proposed [5]. The main diagnostic consideration in our patient is the dialysis-related headache. This form of headache is attributed to disorder of homeostasis and is defined as the headache that starts during HD, resolves within $72 \mathrm{~h}$ after each HD session, ceases after successful transplantation, and develops during at least half of HD sessions [1]. A recent prospective study of more than 300 patients undergoing chronic HD reported low incidence of the dialysis-related headache $(6.6 \%)$ [6].

The next possibility is the recurrent exacerbation of previously existing migrainous headache or developing of episodic tension-type headache triggered by the dialysis treatment. Periodic, unvarying headache induced by HD, personal history of prolific using of black coffee and prompt relief obtained upon the ingestion of caffeine, however, strongly suggested the genuine $\mathrm{CWH}$ in our patient.

The elimination of caffeine from the body is fast and dose-dependent with a typical plasma half-life of 2, 5-4 h [7]. However, the rapid onset of headache provoked by HD in our patient implies significantly faster caffeine elimination that could be explained by rapid removal of caffeine by dialysis. It has been demonstrated that caffeine reduces $\mathrm{CBF}$ in normal individuals and in patients recovering from an acute ischemic stroke [8]. In our patient, the measured blood flow velocities using TCD were within normal range at the beginning and in the end of dialysis session, implying that there was no change in CBF during her dialysis treatment. Measurements were performed bilaterally on middle cerebral artery only, so we have no data about blood flow velocities in the vertebrobasilar circulation which supply caudal trigeminal nuclei. However, the normal response on breath holding tests suggests the preserved vasomotor reactivity thus diminishing the possibility of cerebral circulation redistribution via collaterals during her HD.

In the comprehensive review of caffeine-withdrawal symptoms Juliano and Griffiths summarized 66 studies of which 42 were double-blind experiments. They found that the quality and frequency of headache heavily depended on caffeine maintenance dose and duration of caffeine dosing. In some of these studies, the relevant clinical characteristics of $\mathrm{CWH}$ have been described as being gradual in development, diffuse, throbbing, severe, intensified with exercise and distinct from migraine headache [9]. On the other hand, some authors stated that CWH is mostly mild, bilateral, and with no associated nausea, photophobia or sensation of throbbing [10], which is in accordance with the description of headache obtained from our patient.

Interestingly, the son of our patient has the similar withdrawal headache upon abrupt cessation of habitual coffee usage. This genetic propensity for caffeine-withdrawal symptoms, with an estimated inheritance of $35 \%$, has already been reported [11]. Regardless of its rarity, it should be prudent to consider the possibility of CWH in the uremic patient who regularly consumes large quantities of coffee and suffers from typical headache during each dialysis session.

\section{Conflict of interest None.}

\section{References}

1. Headache Classification Subcommittee of the International Headache Society (2004) Classification and Diagnostic Criteria for Headache Disorders, Cranial Neuralgias and Facial Pain, 2nd edition. Cephalalgia 24(Suppl 1):1-160

2. Sherman RA, Daugirdas JT (2007) Complications during hemodialysis. In: Daugirdas JT, Blake PG, Ing TS (eds) Handbook of dialysis, 4th edn. Lippincott Williams \& Wilkins, Philadelphia, pp 170-191

3. Bana DS, Yap AU, Graham JR (1972) Headache during hemodialysis. Headache 112:1-14. doi:10.1111/j.1526-4610.1972. hed1201001.x

4. Goksan B, Karaaali-Savrun F, Ertan S, Savrun M (2004) Hemodialysis-related headache. Cephalalgia 24:284-287. doi: 10.1111/j.1468-2982.2004.00668.x

5. Antoniazzi AL, Bigal ME, Bordini CA, Tepper SJ, Speciali JG (2003) Headache and haemodialysis: a prospective study. Headache 43:99-102. doi:10.1046/j.1526-4610.2003.03025.x

6. Milinkovic M, Zidverc-Trajkovic J, Sternic N et al (2009) Hemodialysis headache. Clin Nephrol 71:158-163

7. Arnaud MJ (1987) The pharmacology of caffeine. Prog Drug Res $1: 273-313$

8. Ragab S, Lunt M, Birch A, Thomas P, Jenkinson DF (2004) Caffeine reduces cerebral blood flow in patients recovering from an ischaemic stroke. Age Ageing 33(3):299-303

9. Juliano LM, Griffiths RR (2004) A critical review of caffeine withdrawal: empirical validation of symptom and signs, incidence, 
severity, and associated features. Psychopharmacology 176:1-29. doi:10.1007/s00213-004-2000-x

10. Sjaastad O, Bakketeig LS (2004) Caffeine-withdrawal headache: the Vaga study of headache epidemiology. Cephalalgia 24:241249. doi:10.1111/j.1468-2982.2003.00638.x
11. Kendler KS, Prescott CA (1999) Caffeine intake, tolerance, and withdrawal in women: a population-based twin study. Am J Psychiatry 156:223-228 